\title{
Internet, canais de participação e efeitos políticos: um estudo do Portal da Câmara
}

\author{
Francisco Paulo Jamil Almeida Marques ${ }^{1}$
}

\begin{abstract}
O trabalho investiga os efeitos que os usos dos recursos digitais de participação presentes em portais institucionais são capazes de gerar sobre o processo de produção da decisão política. A partir do exame empírico das características e das formas de uso dos canais de input político diagnosticados no Portal da Câmara dos Deputados (Brasil), são questionados os limites da influência que os cidadãos conseguem exercer sobre seus representantes. $\mathrm{Na}$ experiência analisada, descobriu-se que, não obstante a variedade de instrumentos voltados para fomentar a participação, os usuários são dotados de insumos que restringem seus modos de intervenção a atividades como debater, sugerir ou, no máximo, pressionar os parlamentares (isso não é pouco, mas contradiz os discursos mais eufóricos acerca do potencial dos dispositivos digitais). Acredita-se que esta limitação se dá pela força das regras tradicionais que orientam o jogo político, marcadas pela ênfase na democracia representativa.
\end{abstract}

Palavras-chave: internet, participação, instituições políticas.

Internet, participatory tools, and political effects: A study on the Brazilian case. This study examines the political effects that the participatory tools technically provided by the Internet can cause on the institutional decision-making process. Departing from the study of the features and uses of the participatory mechanisms found on the Brazilian House of Representatives website, one considers the limits of the effective influence that citizens are able to exert on the parliament members by using the new media. The research found out that despite the availability of assorted digital mechanisms focused on encouraging participation (e.g. e-mail, web forms, chat rooms, opinion polls, and public forums), users' inputs are narrowed in this case to activities like debating or suggesting with no big consequences at all. One believes that this is so due to the ways how the traditional political game works, emphasizing a strict representative democracy.

Key words: internet, participation, political institutions.
Cette étude examine les effets politiques que les outils participatifs de l'Internet peuvent générer sur le processus de décision politique. En partant de l'étude des caractéristiques et des utilisations des mécanismes de participation au site de la Chambre des Représentants du Brésil, on considère les limites de l'influence réelle que les citoyens sont capables d'exercer sur les membres du Parlement en utilisant les nouveaux médias. La recherche a révélé que malgré la disponibilité des mécanismes participatifs (par exemple l'e-mail, les formulaires, les sondages d'opinion, et les forums publics), les utilisateurs sont rétrécies dans ce cas à des activités comme le débat, l'envoi des suggestions et la pressión sur les parlementaires sans grandes conséquences du tout.

Mots-clés: internet, participation, institutions politiques.

\footnotetext{
${ }^{1}$ Pós-Doutor em Comunicação Social (UFMG). Doutor em Comunicação e Cultura Contemporâneas (UFBA). Professor Adjunto I do Departamento de Comunicação Social da Universidade Federal do Maranhão. UFMA - Campus Universitário do Bacanga, Av. dos Portugueses, S/N, Centro de Ciências Sociais - Departamento de Comunicação Social, 65085-580, São Luís, MA, Brasil. E-mail: marquesjamil@yahoo.com.br.
} 


\section{Introdução}

A questão da participação política dos cidadãos tem se mostrado uma das mais relevantes, tanto para a teoria quanto para a prática democrática contemporânea. Há uma nítida percepção de disposição de governos, movimentos sociais e estudiosos em investir na consecução de mecanismos direcionados a operacionalizar um envolvimento político mais efetivo da esfera civil. Acredita-se que tal inclinação tem a ver com a confluência de um conjunto de circunstâncias paralelas a caracterizarem o perfil do jogo político hodierno.

A primeira dessas circunstâncias se refere à força argumentativa crescente (ainda que esta não seja uma tendência unânime), da qual desfrutam aqueles autores dedicados a defender a instauração de processos mais consistentes de legitimação (Held, 1987; Bohman, 1996; Habermas, 2003; Dryzek, 2004; Nobre, 2004; Avritzer, 2009). A promoção de mecanismos participativos exerce uma influência sensivelmente positiva na avaliação dos regimes democráticos, mesmo se forem consideradas aquelas concepções não alinhadas com a Teoria Crítica (Dahl, 2001). O segundo aspecto diz respeito ao fato de que, nas últimas décadas, apresenta-se, claramente, uma maior profusão de movimentos e organizações sociais que, nos mais distintos eventos e arenas, passaram a tomar parte no planejamento e na execução de políticas públicas em parceria com as instituições do estado. Tal fenômeno resultou em uma associação mais forte entre a ideia de democracia e a promoção de oportunidades consistentes de participação (Gastil, 2000; Souza, 2001; Dagnino, 2002; Fung, 2004; Avritzer, 2007; Coelho, 2007). Em terceiro lugar, o diagnóstico de aperfeiçoamento de determinados valores atinentes à ideia de democracia (como, por exemplo, a maior preservação de direitos, liberdades e o incremento da transparência pública) terminou, por tabela, reforçando a necessidade de se sofisticar o próprio princípio da participação (Bobbio, 2000; Brasil, 2000; Norris, 2000; Freedom House, 2006; Transparency International, 2007). Por último, parte-se do pressuposto de que as facilidades trazidas pelas inovações no campo das tecnologias de comunicação (Hill e Hughes, 1998; Delli Carpini, 2000; Bucy e Gregson, 2001; Coleman e Gøtze, 2001; Krueger, 2002, 2006; Weber et al., 2003; Stanley e Weare, 2004; Gomes, 2005; Marmura, 2008) tendem a atiçar aquelas demandas erigidas no sentido de se corrigir o que é apontado como um problema estrutural das democracias modernas: a rígida separação entre o papel político-decisório da esfera dos representantes (Manin, 1997; Barber, 2004; Vitale, 2007), de um lado, e as funções preponderantemente plebiscitárias destinadas à esfera civil, de outro.

É este o quadro no qual se encaixam as preocupações atinentes aos efeitos dos new media sobre a dimensão participativa das sociedades democráticas, tema do presente artigo. Há uma bibliografia variada a tratar dos meios e modos pelos quais os media digitais tornam disponíveis mecanismos de participação. Seja através do fortalecimento daquelas iniciativas cujo vetor parte da sociedade civil (com vistas, por exemplo, à mobilização) ou do estabelecimento de experiências institucionais direcionadas aos cidadãos (merecendo menção as ofertas de serviços públicos), a cada dia parece ser dado um uso singular a estas tecnologias, o que termina por provocar consequências de distintas dimensões junto aos correntes padrões de atuação política.

Caso caiba a este ponto uma classificação grosseira, a literatura de ponta na área parece ter superado aquela que pode ser tida como a primeira fase da pesquisa em democracia digital, caracterizada pela dicotomia e pela especulação atinente às potencialidades e às ameaças à democracia que os neww media engendram (Negroponte, 1995; Barnett,1997; Buchstein, 1997; Lévy, 1999; Tambini, 1999). A segunda fase da pesquisa esteve voltada, por sua vez, à investigação dos modos pelos quais os mecanismos são efetivamente empregados por agentes do campo político (Norris, 2001; Ferber et al., 2003, 2005; Lipinski e Neddenriep, 2004; Salter,2004). A ênfase mais recente, por sua vez, com a qual este trabalho se esforça para estar alinhado, reconhece tais contribuições anteriores, mas procura lidar com determinadas particularidades, aderindo a uma perspectiva mais equilibrada entre tecnologia e política tradicional. Nessa última tendência, tornam-se pauta de investigação, por exemplo, os constrangimentos que representantes impõem à adoção dos media digitais por parte das instituições do Estado, motivados pelo senso de preservação do poder que os resultados das urnas lhes conferem (Noveck, 2004; Shulman, 2004; Stanley e Weare, 2004).

Este trabalho, por sua vez, investiga um outro tema que se encontra nesta agenda mais recente de pesquisa em democracia digital. Lançando-se mão da discussão conceitual e do diagnóstico relativo à maneira através da qual determinadas experiências empregam os recursos digitais de comunicação, são examinados quais podem ser os reais efeitos que os usos destas tecnologias geram sobre o processo de produção da decisão política. A intenção, em outras palavras, é investigar o alcance e as possíveis consequências políticas que os mecanismos participativos disponíveis em portais de órgãos do Estado, uma vez acionados, são 
capazes de provocar sobre o processo de produção daquelas decisões tomadas em âmbito institucional. Qual seria, então, a contribuição da tecnologia em tais processos? Que resultados concretos, enfim, emergem, por exemplo, dos debates travados em fóruns de discussão digital?

O estudo de caso selecionado para este empreendimento foi o Portal da Câmara dos Deputados (2009). O motivo particular que levou a pesquisa a tal escolha se refere ao fato de que esta iniciativa da Câmara se apresenta como uma das mais bem-sucedidas experiências de democracia digital no Brasil (Braga, 2007; Marques e Miola, 2007; Marques, 2008) e no mundo (ONU, 2008), merecendo destaque por conta da variedade de canais de participação que torna disponível (bate-papo, fóruns, comentário a notícias, encaminhamento de mensagens a parlamentares, dentre outros dispositivos). Conforme aponta um conjunto de autores dedicados às teorias da democracia (Verba et al., 1995; Delli Carpini, 2000), contudo, uma participação efetiva da esfera da cidadania não se refere apenas à disponibilidade de canais de intervenção política. Levando em consideração tal aspecto, é preciso reconhecer o fato de que o Portal da Câmara conta, também, com um aparato informacional sofisticado no que se refere a conferir visibilidade as suas características, história e funções dentro da estrutura do Estado Brasileiro. A iniciativa oferece, então, informações de cunho institucional e sobre as atividades cotidianas dos operadores políticos que atuam na Casa; porém, percebe-se o esforço desta experiência em dar ao cidadão a possibilidade de acompanhar o trabalho dos deputados no Plenário e nas comissões, através de transmissão ao vivo das sessões ou da fiscalização dos gastos realizados pelos gabinetes. São estas características que fustigam um questionamento mais detalhado acerca da real influência que os cidadãos conseguem gerar sobre o campo político e sobre os representantes, uma vez que empregam tais mecanismos.

A hipótese a ser investigada se refere à ideia de que, para a consecução de um tipo de participação civil destinada a exercer efeitos consistentes sobre as decisões que são tomadas na Câmara, é preciso ir além da oferta de recursos digitais de participação, por mais avançados que eles sejam ou ainda que de seu uso tomem parte representantes eleitos. Isso porque, não obstante os avanços do ponto de vista tecnológico, persistem barreiras como, por exemplo, o perfil eminentemente representativo das democracias modernas (Miguel,2003), que tendem a anular, em boa parte das vezes, o poder de influência que os dispositivos disponíveis seriam capazes de gerar. Tal concepção reforça a ideia de que, por trás do desenho daqueles instrumentos e recursos digitais presentes em websites institucionais, há uma concepção pragmática de democracia (que pode se mostrar mais ou menos adepta àquelas investidas participativas mencionadas no início do texto) a orientar os processos decisórios que têm lugar no âmbito do Estado.

A pesquisa empírica se fundamenta em uma investigação qualitativa da experiência em tela neste artigo.Para averiguar os possíveis efeitos políticos que as ferramentas participativas disponíveis no Portal da Câmara podem gerar, lançou-se mão (i) de análise documental (foram pesquisados os princípios e diretrizes mais candentes a orientarem a iniciativa e a regerem a configuração do website e de suas ferramentas, bem como os relatórios anuais a medirem o desempenho do Portal); (ii) de entrevista com os principais responsáveis pelo Comitê Gestor do site da instituição; (iii) de visita monitorada ao website entre setembro de 2007 e abril de 2008, a partir da qual foi feito um levantamento e um acompanhamento dos recursos disponíveis e de suas configurações; e, ainda, (iv) estabeleceu-se uma avaliação discursiva das conversações mantidas entre representantes e usuários, tanto no principal fórum público abrigado no Portal, até então, quanto nas 44 conversações realizadas em salas de bate-papo entre 2005 e 2007. Considera-se, particularmente, que estas duas ferramentas revelam de forma mais exata os indícios aptos a responderem a questão que direciona a presente pesquisa.

A primeira parte do artigo empreende um diagnóstico conciso das principais ferramentas de participação presentes no Portal da Câmara. No tópico seguinte, são confrontadas as expectativas democráticas que gestores e representantes atribuem aos new media com as limitações práticas verificadas no uso destes mecanismos, no que tange à reverberação sobre as decisões. A terceira seção retoma a reflexão teórica que fundamenta as ressalvas até então apontadas. E, por fim, espera-se ter reforçado a perspectiva que se volta à existência de uma influência mútua entre tecnologia e práticas da democracia.

\section{Uma avaliação dos recursos participativos do Portal da Câmara}

Não obstante as expectativas positivas de uma parcela considerável dos estudos em democracia digital, há um conjunto de autores argumentando que a grande 
maioria dos projetos institucionais reflete apenas de maneira escassa as capacidades de aperfeiçoamento político auferidas pelos new media (Strommer-Galley, 2000; Salter, 2004; Ferber et al., 2005). Scheufele e Nisbet (2002), por exemplo, afirmam que, no atual estágio das iniciativas que vêm sendo desenvolvidas, o papel dos recursos de Internet continua mínimo. São poucos os casos nos quais são encontrados mecanismos mais aprofundados de participação a permitirem uma interação além daquela viabilizada pelo e-mail.

Mas a escassez de recursos participativos averiguada em muitas das experiências não significa que os governos estão pouco atentos aos benefícios trazidos pela tecnologia digital. Na verdade, sabe-se que determinadas instituições estabelecem prioridades diferenciadas quanto ao emprego dos recursos digitais. No âmbito do Poder Executivo Federal brasileiro, por exemplo, os empreendimentos voltados para aumentar a arrecadação de impostos, impor maior rigor à fiscalização e otimizar processos internos encampam inovações, muitas vezes, pioneiras em termos mundiais de governo eletrônico ${ }^{2}$.

Nesse sentido, estudiosos como Musso et al. (2000) reafirmam a ideia de que cada projeto de democracia digital acaba refletindo um planejamento específico, isto é, a configuração de cada iniciativa responde a demandas e a prioridades que foram inicialmente traçadas pelos próprios agentes institucionais. Ao pesquisarem empiricamente o modo pelo qual foram projetadas e postas em operação experiências de governo eletrônico em diferentes municipalidades, estes autores perceberam que há casos de cidades que dão privilégio aos assuntos da esfera econômica (oferecendo todo o tipo de informação e serviços necessários a empreendedores e consumidores); por outro lado, iniciativas participativas ou atinentes à dimensão político-democrática foram, na maioria das vezes, colocadas em segundo plano.

$\mathrm{Na}$ contramão das conclusões apresentadas logo acima, o Portal da Câmara dos Deputados consiste em uma das poucas experiências brasileiras a demonstrarem maior ousadia quanto à oferta de recursos de participação voltados para fomentar um relacionamento político diferenciado entre cidadãos e representantes. A iniciativa vem se destacando em distintas avaliações por sua ênfase tanto na dimensão informativa (explicação de termos técnicos, tutoriais acerca de como funciona o processo legislativo, transparência nos gastos) quanto na dimensão participativa.
A primeira versão do Portal foi concebida em 1996, mas só em 2004 a Câmara passou a se dedicar à instauração de uma gestão mais especializada de seu conjunto de sites. Naquele ano, uma comissão foi nomeada no intuito de promover um chamado "salto qualitativo" no Portal, tendo como uma de suas metas fundamentais refletir acerca de quais seriam os melhores meios para se conferir maior transparência e visibilidade às atividades desempenhadas na Casa, bem como para se azeitar a interação com a esfera civil. De acordo com o relatório elaborado por esta comissão:

O sitio da Câmara dos Deputados é ferramenta estratégica de comunicação com o cidadão. Apesar de o recurso web não estar disponivel para a maior parte da população brasileira, é de fundamental importância prover a página da instituição de mecanismos de participação popular, de forma a confirmar e incentivar a prática democrática e o exercício da cidadania. De acordo com esta perspectiva e com base nas demandas de comunicação atualmente dirigidas aos serviços 0800, Carta-Resposta e demais canais de atendimento da Casa, propóe-se a multiplicação dos recursos de participação atualmente oferecidos pelo sítio (Brasil, 2004, p. 19).

A partir de 2005, um Comitê Gestor, integrado por diversos setores da Casa, passou a administrar o site e implementou uma série de melhorias, tanto no que se refere ao cultivo do repertório informacional dos visitantes do Portal quanto em relação ao desenvolvimento de recursos participativos.

A pesquisa empírica realizada entre setembro de 2007 e abril de 2008 (Marques, 2008) permitiu descobrir que a ferramenta mais comumente oferecida nesta iniciativa é o endereço de e-mail e seu congênere, o formulário digital para contato. Estes dois mecanismos se voltam para permitir a interação dos usuários com os diversos setores da Casa ou com os próprios parlamentares. Entre 2005 e 2007, o número de mensagens enviadas apenas por meio do Fale com o Deputado saltou de 2,6 milhões para mais de 10 milhões, demonstrando a popularidade do canal (Brasil, 2006, 2008). Salienta-se, por um lado, que tais ferramentas se mostram mais eficazes no caso de consultas ou do encaminhamento de demandas particulares. Por outro lado, observa-se que esta modalidade de contato fomenta uma

${ }^{2}$ Consulte-se, por exemplo, os portais ComprasNet (2008) e o da Receita Federal (2008). 
abordagem mais individualista aos agentes a integrarem a Câmara, sem maior adequação a tarefas como, por exemplo, a discussão pública de questões de concernência coletiva.

A possibilidade de se adicionar comentários a notícias publicadas pela Agência de Notícias da Câmara é mais um dos mecanismos a estimularem a participação dos usuários, que têm a chance de interagir com parlamentares e com outros cidadãos em tópicos pautados pelos acontecimentos recentes (aprovação de projetos, discussão em comissões) que tiveram lugar na Casa.

As sondagens de opinião, por sua vez, também são organizadas pela Agência Câmara e enfatizam temas polêmicos e atuais, provendo ao visitante a oportunidade de votar e de verificar o posicionamento dos outros usuários acerca de uma questão específica. Dentre as enquetes de maior repercussão que atraíram um público numericamente superior, pode ser citada aquela a indagar a opinião do cidadão quanto ao comércio de armas e munição no Brasil, que computou 6613 votos, entre 03 e 13 de outubro de 2005.

Com relação aos fóruns digitais de discussão pública, um dos canais de participação mais sofisticados encontrados na experiência em tela, pode-se enfatizar sua capacidade de fomentar a existência de um espaço com a capacidade de incluir um conjunto razoavelmente amplo de cidadãos e deputados, de forma não instantânea e com um espaço maior para o desenvolvimento de argumentos. No intervalo entre 2005 e 2007, três Comissões da Câmara foram responsáveis pela moderação de oito fóruns. O fórum que gerou maior repercussão foi aquele administrado pela Comissão de Legislação Participativa, tema de reflexão neste artigo.

As salas de bate-papo, por sua vez, têm um perfil semelhante àquele dos fóruns. Em todos os 44 chats promovidos entre 2005 e 2007, foi possível constatar a existência de trechos nos quais são solicitados esclarecimentos (detalhes sobre o tema do chat, sobre os debates travados no Congresso ou acerca da tramitação de matérias) e onde o congressista é inquirido em relação a seu posicionamento político. Dada sua característica síncrona, todavia, o bate-papo não favorece a construção de argumentos em maior extensão. Ou seja,nos chats, dificilmente é possível desenvolver ideias de maneira mais aprofundada, visto que os agentes em interação têm apenas alguns instantes para se expressar, sem a possibilidade de procurar informações adicionais para alicerçar reflexões.
Por outro lado, os chats contam com uma gama ideológicopartidária mais variada de parlamentares.

Ao fim, acredita-se que, por terem diferentes aplicações, modos de funcionamento e maneiras de fomentar atividades políticas, os fóruns e as salas de bate-papo merecem atenção especial, uma vez que agregam peculiaridades importantes em relação àqueles outros mecanismos tratados anteriormente. Por tornarem mais evidente um estreitamento da interação entre representantes e representados, estes dois canais são mais detalhadamente examinados a fim de se investigarem os efeitos que seus usos podem gerar sobre o processo de produção da decisão política abrigado na Câmara dos Deputados.

\section{Canais digitais de participação política: um exame de seus efeitos políticos}

Conforme pôde ser observado no tópico anterior, o Portal da Câmara investe na oferta de mecanismos de participação na expectativa de estabelecer uma sintonia mais fina entre o parlamento e a sociedade. Dois dos principais responsáveis pelo Comitê Gestor do Portal em 2007, Cássia Botelho e José Antônio Ferreira Filho afirmaram, em entrevista para a pesquisa que deu origem a este artigo, que (i) a iniciativa por eles administrada oferece aos cidadãos recursos adequados para acompanhar a atuação de seus representantes e para participar em escala individual ou coletiva. Os gestores consideram, ainda, que (ii) os usuários vêm empregando em boa medida os mecanismos participativos oferecidos através do Portal $^{3}$ e que (iii) em determinadas ocasiões, a esfera civil, ao lançar mão de tais dispositivos, exerce uma influência destacável sobre o processo de discussão e de produção da decisão política.

O tópico anterior se dedicou a esclarecer o primeiro ponto da argumentação dos administradores da iniciativa. De fato, a variedade e a profundidade dos dispositivos digitais voltados para fomentar a participação justificam as avaliações positivas que a experiência recebe em relatórios nacionais e internacionais. Quanto ao segundo

\footnotetext{
${ }^{3}$ Não obstante, os entrevistados percebem a existência de certo tipo de público que participa com maior afinco (sobretudo, jovens e cidadãos com grau universitário).
} 
argumento indicado pelos gestores, também não parece haver dúvidas, considerando-se, por exemplo, os números atinentes à crescente quantidade de mensagens enviadas pelos usuários aos parlamentares.

O essencial para este trabalho, contudo, aparece na terceira alegação dos responsáveis pelo Portal, aquela relativa à afirmação de que o emprego de recursos de participação por parte dos usuários vem repercutindo na formulação das decisões políticas tomadas no âmbito da Câmara.Uma série de exemplos foi apontada pelo Comitê Gestor (tanto por meio de entrevista quanto através da disponibilidade de relatórios anuais acerca das atividades do Portal (Brasil, $2005,2006,2008)$ na intenção de ressaltar o caráter participativo da iniciativa e os efeitos que o envolvimento dos usuários gera. Ao indicar a importância do recurso Comente esta notícia, por exemplo, Cássia Botelho afirma que:

\section{[...] muitos projetos de lei que já foram alterados, porque} o cidadão mandou uma observação. Ai eu mando isso pro deputado, que é o relator da matéria [...] Às vezeso deputado não tinha pensado [naquela razão apontada pelo usuário] [...] [Com] muitas pessoas pensando, você tem condição de construir algo melhor [a partir da intervenção dos cidadãos] (Botelho e Ferreira Filho, 2007).

De modo a reforçar esta disposição, constatou-se que determinados representantes eleitos afirmaram, por meio de entrevista ou mesmo ao longo do curso do emprego de alguns dos mecanismos apontados, verem com bons olhos certas sugestões dos usuários, dando a entender, assim, que tais contribuições são efetivamente levadas a sério. É o caso da deputada Sandra Rosado, do Partido Socialista Brasileiro (PSB), que relatou, em entrevista concedida à TV Câmara, contar com uma equipe própria para processar as respostas para as perguntas enviadas pelos cidadãos por intermédio da Internet (o que já rendeu, conforme depoimento da parlamentar, a elaboração de projetos de lei de sua autoria ${ }^{4}$ ).

Os fóruns e as salas de bate-papo, igualmente, permitem apreender tal inclinação quando, por exemplo, vários deputados induzem os cidadãos a acessarem o Portal da Câmara a fim de obterem informações mais aprofundadas sobre pontos destacados nos debates digitais. Tal atitude demonstra que há congressistas a par dos recursos disponíveis no Portal e que se esforçam em integrar suas atividades a estes artifícios ${ }^{5}$.

[Sala de bate-papo]

Data: 03/07/2007

Tema: Direito de greve do servidor público

Participante: Deputado Nelson Marquezelli (PTB-SP)

L. Fala com TODOS: Deputado, não tive a oportunidade de ler o seu relatório. Acho muito importante a regulamentação do direito de greve, pois o serviço público nem sempre é totalmente justo com o servidor. Não são só as empresas privadas que falham com seus empregados.

Dep. Marquezelli: L., leia nosso relatório na página da Câmara. Acesse www.camara.gov.br, opção "projetos de lei e outras proposições". Digite, então, o número do projeto (PL 4497, de 2001) e você estará na página de sua tramitação, onde poderá consultar meu relatório.

As discussões que têm lugar nas salas de batepapo e nos fóruns permitem, adicionalmente, verificar a importância que determinados parlamentares auferem às contribuições dos usuários. Deparou-se com uma situação na qual a participação através dos media digitais foi solicitada enquanto fator de pressão junto a outros representantes. No caso, o deputado Arnaldo Faria de Sá (Partido Trabalhista Brasileiro) apelou, em sala de bate-papo, para que fossem utilizadas diversas formas de contato (inclusive os mecanismos de comunicação digital), a fim de se obter votos favoráveis à aprovação de um projeto de emenda à Constituição voltado para combater o nepotismo.

[Sala de bate-papo]

Data: 05/09/2005

Tema: PEC do Nepotismo

Participante: Deputado Arnaldo Faria de Sá (PTB-SP)

L.A.C.: Deputado: Gostaria de alertá-lo que muitos prefeitos e vereadores nomeiam seus parentes em municipios vizinhos e recebem, em suas folhas, parentes dos prefeitos e vereadores de municipios vizinhos. Como evitar essa contratação nepótica cruzada?

\footnotetext{
${ }^{4}$ Entrevista à TV Câmara concedida no dia 7 de maio de 2007 (TV Câmara, 2007).

${ }^{5}$ Decidiu-se por preservar os nomes dos usuários que enviaram intervenções aos fóruns, sendo exibidas apenas as iniciais dos nomes ou apelidos com os quais eles se identificaram. Ressalte-se, ainda, que, deliberadamente, não houve correção textual das mensagens enviadas, na intenção de se manter a fidelidade ao conteúdo original.
} 
Dep. Faria de Sá: L., agradecemos a sua sugestão e ponderamos que a nossa proposta contempla a proibição das denominadas nomeações cruzadas ou de reciprocidade. Ressaltamos que fomos extremamente rigorosos no tocante à essa prática, proibindo nomeações triangulares, quadrangulares e terceirizadas. Esperamos o seu apoio à nossa proposta, o qual poderá ser manifestado pelo envio de e-mails aos demais parlamentares dessa Casa.

Estas manifestações dão provas de que os canais de input participativo patrocinados pelo Portal da Câmara estão, em diferentes ocasiões, sendo empregados. Por outro lado, a questão examinada neste artigo se refere não necessariamente ao diagnóstico acerca da variedade de recursos ou ao estímulo de seus usos, mas ao exame acerca do real grau de influência destes encaminhamentos feitos pelos cidadãos.

Acredita-se que a boa vontade da instituição e de alguns representantes em interagir ou em estimular o envolvimento político, exposta nas oportunidades acima mencionadas, não pode ser, necessariamente, traduzida em termos de consequências, efeitos ou reverberações mais profundas sobre a produção de políticas. A pesquisa empírica preliminar permite, de fato, perceber determinados eventos nos quais os usuários exercem algum grau de influência sobre os parlamentares (enviar e-mails, por exemplo).

Argumenta-se, contudo, pela necessidade de compreender de forma mais detida o alcance destes mecanismos de influência, refinando-se, assim, o estudo qualitativo dos recursos tornados disponíveis para a participação nesse caso. Isto é, tomando-se a inequívoca inclinação da Câmara em promover, das mais variadas formas, ocasiões interativas entre representantes e esfera civil, resta investigar as reais consequências de tais contribuições e seus resultados do ponto de vista da elaboração das decisões de cunho político.

\section{Controle de fronteiras: limites da participação digital}

De início, pode-se dizer que, excetuando-se ocasiões pontuais, as ferramentas de participação presentes no Portal da Câmara provocam, em geral, mais uma forma de pressão sobre os parlamentares do que propõem um modo de intervenção direta da esfera civil na formatação da decisão política. Os dispositivos digitais de participação diagnosticados neste caso apresentam, assim, melhores condições (i) de fortalecer o oferecimento de insumos (sobretudo, informacionais) à participação dos usuários nos debates e (ii) de permitir a concatenação de pressões sobre os mandatários (seja através de campanhas de envio em massa de mensagens, de resultados em sondagens de opinião pública ou do encaminhamento de apelos).

O estudo dos diálogos travados nas salas de batepapo e nos fóruns públicos de discussão permite constatar, por exemplo, que aqueles mesmos parlamentares que se mostram sensibilizados com a urgência em incrementar a participação dos usuários, acabam, por outro lado, rechaçando aquelas sugestões de alguns usuários a insinuarem a instauração de processos mais diretos de democracia. A questão de fundo a ser considerada aqui trata das barreiras impostas a qualquer tentativa de se modificar a estrutura de exercício do poder político que caracteriza as práticas democráticas modernas.

[Fórum de discussão]

Estou entusiasmada com sua participação! por Deputada Fátima Bezerra (29/07/2005 10:42)

A democracia participativa tal qual realizada na Grécia e na Roma antiga é inviável nos dias de hoje - a não ser em pequenas populaçóes, como na Suiça, por exemplo. As sociedades são mais complexas e, como no caso do Brasil, muitas são pertencentes a países de vasta extensão territorial. [...] A democracia representativa, portanto, é o meio de que dispomos atualmente para que, mesmo de forma indireta, possamos exercer o legitimo direito de interferir nos destinos da sociedade.

Há parlamentares que expressam de modo mais claro sua perspectiva voltada para defender a manutenção na divisão do trabalho político, demonstrando disposição em enfatizar que a palavra final é do Plenário no qual atuam.

[Sala de bate-papo]

Data: 28/11/2006

Tema: Voto Secreto

Participante: Deputado José Eduardo Cardozo (PT-SP)

gasóleo: Insisto, se estamos em uma democracia porquê o povo nunca échamado para participar diretamente do 
processo eleitoral por meio do plebiscito e do referendum? Dep. Cardozo: Gasóleo, tanto o plebiscito como o referendo são instrumentos de participação direta da população previstos na Constituição. Recentemente, pudemos exercitar essa participação no referendo sobre a comercialização de armas no Brasil. Trata-se de um instrumento que poderia de fato ser mais utilizado, sobretudo em questöes de grande relevância nacional. De qualquer forma, a regra da natureza da democracia representativa é a escolha dos parlamentares para expressar a vontade popular.

[Sala de bate-papo]

Data: 22/02/2006

Tema: Reforma sindical

Participante: Deputado Tarcísio Zimmermann (PT-RS)

L.: Na opinião do senhor, qual o caminho para superar tantas divergências e chegar a uma proposta que reúna um minimo de consenso?

Dep. Zimmermann: L., não há possibilidade de superar as divergências. Tentamos regulamentar a organização sindical tendo como fundamento os princípios da democracia, da cidadania, da participação politica e social, da representatividade, do direito ao trabalho digno, da valorização da negociação coletiva entre trabalhadores e empregadores e da promoção dos direitos fundamentais. Mas o texto a que chegaremosé sempre uma decisão politica dos parlamentares.

Mesmo com a dedicação do Portal em cultivar habilidades políticas e o repertório informacional dos usuários, elas não parecem ser vistas por alguns deputados como suficientes para permitir uma intromissão mais abalizada em determinados temas. Há ocasiões nas quais se sobressai a ideia de que certas decisões possuem um cunho eminentemente técnico, devendo-se considerar, de acordo com o argumento colocado pelos representantes, as complicações em envolver os cidadãos na formulação de políticas públicas tão especializadas.

[Sala de bate-papo]

Data: 06/04/2006

Tema: TV digital

Participante: Walter Pinheiro (PT-BA)

O.: Por que esse assunto não é debatido em um plebiscito nacional, como o infeliz plebiscito sobre armas? Seria mais democrático e esclarecedor.
Dep. Pinheiro: O., a sua proposta de um plebiscito é bastante interessante. Entretanto, a complexidade das definições que compõem o sistema brasileiro de TV digital poderiam inviabilizar essa prática democrática de submeter ao povo brasileiro diretamente à escolha de uma infinidade de variáveis responsáveis pela implementação da TV digital.

Observa-se que a questão de fundo revelada por tais disposições tem a ver com a manutenção do princípio de que a produção final da decisão política reside, não obstante o oferecimento de informações, estímulos à interação e de canais participativos de input, nos mandatos dos representantes. Assim, não é porque reconhecem a necessidade de se promover um maior envolvimento político da esfera civil para uma formulação mais legítima das políticas públicas ou porque tomam parte no uso dos mecanismos digitais que estes agentes se mostram dispostos a ir muito além da viabilização de ferramentas de interação e de consulta. Por fim, o resultado máximo oferecido pelos dispositivos de participação encontrados em uma das experiências mais relevantes em democracia digital é a possibilidade de exercer pressão política.

Dois apontamentos são fundamentais neste sentido. Primeiramente, não se pode pensar que os cidadãos estão alheios a sua posição no jogo democrático. Uma das insatisfações mais evidentes apresentadas pelos usuários dos fóruns e das salas de bate-papo se refere ao seu baixo senso de eficácia política (Almond e Verba, 1963), causado pela escassa crença de que suas contribuições serão realmente levadas em conta. A verificação de tal descontentamento se dá nas duas passagens a seguir:

[Fórum de discussão]

Comunicação direta, nacional e econômica.

por C.A.A. (28/04/2005 17:36)

A participação popular e legislação participativa, eu, $e$ acredito que muitos brasileiros iniciaram há muito tempo através do meio mais econômico de comunicação, o e-mail. O problema com este veículo, é que trata-se de via de mão uinica. Com raríssimas exceções, recebemos as respostas ou somos atendidos em nossas reinvindicaçôes.

[Fórum de discussão]

Sugestão: Opinar sobre Projetos de Leis, PEC, EMENDAS ETC. por M.V. (17/10/2005 18:43) 
Sei que vocêpode mandar um e-mail para um ou mais deputados, mas quem garante que ele leu, pode ser o seu assessor, secretária que leu, não achou que fosse interressante e jogou fora. [...] Defendo que seja feito pelo sitio da camara pois, poderia ter um protocolo, $A$ Comissão de Legislação Participativa juntaria um número de e-mail sobre o mesmo assunto e passaria para o DEPUTADO.

Assim, em determinadas intervenções, os participantes demonstram, ainda que haja uma farta disponibilidade de recursos (e mesmo com a insistência de parlamentares para que sejam empregados os recursos digitais), não confiar em seu poder de influência. Foram averiguadas oportunidades em que a descrença dos usuários se mostra de forma a detratar a própria iniciativa de se estabelecer um fórum de discussão abrigado no Portal da Câmara, acusando-se a experiência de tentativa de cooptação eleitoral, conforme depoimento a seguir:

[Fórum de discussão]

DEMOCRATIZAR?

por S.M.R.G. (29/07/2005 10:06)

Senhores parlamentares, mais uma vez parabenizo esta iniciativa, mas por favor levem a sério, não queiram somente estudar o grau de inteligência das pessoas para ver como e onde agir [com fins politicoeleitoreiros].

Em segundo lugar, é preciso sublinhar um argumento fundamental para que não se acuse este trabalho de necessariamente crítico da forma representativa de democracia: oferecer aos usuários insumos para o exercício de pressão sobre parte das atividades dos agentes políticos não é pouco. Reclamar efeitos e consequências políticas mais incisivas ou a transferência do poder de decisão para os cidadãos pode até preencher os anseios de determinadas perspectivas teóricas (Barber, 2004; Arnstein, 1969), mas tal requisição integraria, por outro lado, o fundamento para se questionar a própria existência das instituições e do sistema representativo, o que não parece plausível para as democracias de massa contemporâneas.
Não se está defendendo, assim, a ideia de que a promoção de mecanismos mais diretos de democracia através dos media digitais seria algo superior ou que daria um status mais elevado às iniciativas aqui examinadas. A intenção, na verdade, é apenas mostrar que os recursos digitais de participação têm se voltado mais para a reforma e para o complemento do processo de produção da decisão política (que, no sistema representativo, continua sob responsabilidade de um corpo eleito pelos cidadãos) do que para sua revolução ou para uma transformação mais ampla de seu caráter.

O próximo tópico busca sustentar o argumento de que o jogo político destinado a exercer efetiva influência e controle sobre as decisões tomadas em âmbito institucional continua tendo como players principais os mandatários eleitos, uma vez que a concepção moderna de democracia eminentemente representativa é o principal molde a orientar os projetos de participação digital.

\section{"O que o jogo dá, o jogo leva": representação e participação digital}

É provavelmente pensando em tais limitações que autores como Coleman e Gøtze (2001), Noveck (2004), Musso et al. (2000), mesmo ao se depararem com uma oferta generosa de canais, sublinham a necessidade de se prospectar, desenhar e tornar disponíveis mecanismos mais eficazes a permitirem uma intervenção substantiva por parte dos usuários ${ }^{6}$. Ao se procurar esclarecer, desta forma, qual a efetiva reverberação provocada pelo emprego dos recursos disponíveis no Portal da Câmara, são fortes os indícios a apontarem para a manutenção da função da esfera civil enquanto conjunto de agentes a endereçar contribuições pontuais ao processo de produção de políticas.

Argumenta-se que este fenômeno esconde por trás de si um problema mais de cunho político do que tecnológico, a implicar a necessidade de se compreender fatores como a concepção de democracia que motiva (ou desmotiva) as disposições participativas dos agentes repre-

\footnotetext{
${ }^{6}$ De acordo com Coleman e Gøtze (2001, p. 23, tradução minha), "Fortalecer a representação através de um processo contínuo de discussão e de consulta digital não se refere simplesmente a dar aos cidadãos melhores oportunidades de serem ouvidos - ainda que esse seja um bom começo. Na verdade, a questão é relativa a dar aos cidadãos a posse de sua representação. Refere-se aos cidadãos enquanto agentes a compartilharem o poder, em vez de apenas consumidores de políticas".
} 
sentativos. Mais especificamente, para exemplificar, ainda que o Portal da Câmara passasse a organizar com uma frequência maior eventos como conversas em salas de batepapo ou em fóruns de debate, não seria possível garantir que os parlamentares a tomarem parte em tais eventos demonstrassem a mesma inclinação em considerar os argumentos e reivindicações apresentados pelos cidadãos. Isto leva ao argumento de que há um limite, um ponto de saturação, na capacidade dos media digitais em aprimorar certos valores integrantes da ideia de democracia.

O fundamento desta ressalva remete à ideia mais geral de que muitas das dificuldades a afligirem as práticas políticas contemporâneas têm origem nos quadros sociais e culturais a caracterizarem os diferentes regimes democráticos. Autores como Hill e Hughes (1998) e Arterton (1987) alegam, já há algum tempo, e com alguma razão, que, dificilmente, pode-se atribuir à Internet e as suas potencialidades a capacidade de promover modificações decisivas no comportamento político de cidadãos e representantes. Tal pretensão se mostra menos plausível ainda quando se trata de alterações na cultura política a marcar o jogo democrático abrigado em cada sociedade ${ }^{7}$.

Por fim, corrobora-se a ideia de que, por mais aperfeiçoadas que sejam estas ferramentas, elas não se encontram imunes aos traços que caracterizam o processo tradicional de elaboração, discussão e aprovação, por exemplo, de um projeto de lei. Ademais, não se pode esquecer que as oportunidades participativas ofertadas através da Internet, conforme configuração corrente na experiência aqui investigada, são apenas uma parcela a integrar todo o processo de produção da decisão política que ocorre nos âmbitos institucionais.

Por último, destaca-se que há fatores distintos a influenciarem os padrões de participação na Internet, partindo-se desde a maior ou menor motivação de cidadãos em se envolverem politicamente, passando-se pelo desenho institucional de ferramentas e de recursos apropriados e chegando-se até a própria predisposição particular de cada parlamentar em dialogar abertamente com os usuários.

Assim, acredita-se que aqueles projetos direcionados ao incremento de oportunidades de participação terão maior chance de sucesso, caso levem em conta as dificuldades internas (inclinação dos agentes políticos) e externas (cultura e tradições políticas) impostas a tais empreendimentos. Uma saída plausível se mostra não na tentativa apressada de provocar transformações políticas mais profundas a partir do emprego das tecnologias digitais, mas em um planejamento cuidadoso que paulatinamente convide os representantes (principalmente aqueles mais resistentes) a conhecerem os benefícios que a Internet pode trazer para as práticas democráticas.

\section{Conclusão}

O objetivo deste trabalho foi realizar um estudo acerca das possíveis consequências políticas que as ferramentas de participação disponíveis no Portal da Câmara, uma vez acionadas, têm a capacidade de gerar. A meta foi refletir acerca dos alcances e dos tipos de efeitos que o envolvimento dos cidadãos, realizados mediante intervenções por e-mail, salas de bate-papo, fóruns e outros dispositivos, exerce sobre o processo de produção da decisão política.

Por um lado, o encorajamento do uso dos dispositivos digitais de comunicação, seja por conta da instituição ou do parlamentar, causa uma boa impressão, na medida em que integra estas ferramentas às práticas políticas tradicionais. Por outro lado, nota-se que, mesmo naquelas situações nas quais pode ser presumida uma maior boa vontade dos órgãos do Estado e de seus agentes em ouvir e em interagir com o cidadão, não é possível afirmar que, de fato, os recursos de comunicação digital voltados para a participação política têm a capacidade de tornar os cidadãos politicamente emporwered (Fung, 2004).

De tal modo, mesmo nas experiências onde se verificou farta disponibilidade de oportunidades de participação, como o Portal da Câmara,é possível se questionar se os efeitos reais das contribuições dos cidadãos vão muito além da realização de consultas, da promoção de debates, do encaminhamento de sugestões e do desenvolvimento de atividades voltadas à pressão sobre os representantes.

${ }^{7}$ Conforme Arterton (1987,p. 28), "Há uma relação complicada entre necessidades sociais, padrões culturais, constrangimentos econômicos e capacidades da tecnologia, fazendo com que as tecnologias, isoladamente, não sejam preponderantemente determinantes de sua aplicação política” (Papacharissi, 2002, p. 20, tradução minha), por sua vez, afirma que "Tecnologias relacionadas à Internet podem, certamente, ajudar a conectar, motivar e organizar a divergência. Se a expressão de discordância é poderosa o suficiente para produzir mudanças de efeitos sociais é uma questão de atividade humana e um tema ainda mais complexo. Novas tecnologias oferecem ferramentas adicionais, mas elas não podem, num passe de mágica, transformar a estrutura econômica e política que tem florescido por séculos". 
Isso não é pouco, mas deve-se admitir, com o cuidado de considerar a necessidade e a importância da representação democrática, que estas ferramentas atingem um ponto de saturação que nega aquelas acepções mais eufóricas a ressaltarem um patamar de igualdade entre representantes e representados com o advento dos new media.

\section{Referências}

ALMOND, G.; VERBA, S. 1963. The civic culture: Political attitudes and democracy in five nations. Princeton, Princeton University Press, $379 \mathrm{p}$.

ARNSTEIN, S. 1969. A ladder of citizen participation. Journal of the American Planning Association, 35(4):216-224.

http://dx.doi.org/10.1080/01944366908977225

ARTERTON, C. 1987. Teledemocracy: Can technology protect democracy? Newbury Park, Sage,

AVRITZER,L.2007. Sociedade civil, instituições participativas e representação: da autorização à legitimidade da ação. Dados, 50(3):443-476.

http://dx.doi.org/10.1590/S0011-52582007000300001

AVRITZER, L. 2009. Participatory institutions in democratic Brazil. Baltimore, Johns Hopkins University Press, 205 p.

BARBER, B. 2004. Strong democracy: Participatory politics for a new Age. Berkeley, University of California Press, $320 \mathrm{p}$.

BARNETT, S. 1997. New media, old problems. New technology and the political process. European Journal of Communication, 12(2):193-218.http://dx.doi.org/10.1177/0267323197012002003 BOBBIO, N. 2000. O futuro da democracia. 9a ed., Rio de Janeiro, Paz e Terra, $207 \mathrm{p}$.

BOHMAN, J. 1996. Public deliberation: Pluralism, complexity and democracy. Cambridge, MIT Press, 303 p.

BOTELHO, C.; FERREIRA FILHO, J.A. 2007. Entrevista com o Comitê Gestor do Portal da Câmara. Brasília, novembro de 2007. Entrevista concedida ao autor desta pesquisa.

BRAGA, S. 2007. O papel das TICs na institucionalização das democracias: um estudo sobre a informatização dos órgãos legislativos na América do Sul com destaque para o Brasil. Brasília, CEDI/ Plenarium, $102 \mathrm{p}$.

BRASIL. 2000. Lei Complementar no 101, de 04.05.2000 (Lei de Responsabilidade Fiscal). Brasília, Senado Federal, Centro Gráfico, $25 \mathrm{p}$.

BRASIL. 2004. Relatório do salto qualitativo do sítio da Câmara dos Deputados. Acesso em: 25/01/2008, disponível em: http:// www2.camara.gov.br/sobreoportal/gestaoportal/relatorios/ relatorio-grupotrabalho-primoramento-sitio.pdf.
BRASIL. 2005. Comitê Gestor do Portal da Câmara dos Deputados - Relatório Executivo 2005. Acesso em: 15/04/2008, disponível em: http://www2.camara.gov.br/sobreoportal/gestaoportal/ relatorios/relatorio-atividades-comitegestor-portal-2005.pdf. BRASIL. 2006. Comitê Gestor do Portal da Câmara dos Deputados - Relatório Executivo 2006. Acesso em: 15/04/2008, disponível em: http://www2.camara.gov.br/sobreoportal/gestaoportal/ relatorios/relatorioatividades-comite-gestor-portal-2006.pdf.

BRASIL. 2008. Comitê Gestor do Portal da Câmara dos Deputados - Relatório Executivo 2007. Acesso em: 15/04/2008, disponível em: http://www2.camara.gov.br/sobreoportal/gestaoportal/ Relatorio\%20Executivo\%202007.pdf.

BUCHSTEIN, H. 1997. Bytes that bite: The internet and deliberative democracy. Constellations, 4(2):248-263.

http://dx.doi.org/10.1111/1467-8675.00052

BUCY, E.P.; GREGSON, K.S. 2001. Media participation: A legitimizing mechanism of mass democracy. Nerw Media $\mathcal{E}$ Society, 3(3):357-380.

COELHO, V.S.2007. A democratização dos Conselhos de Saúde: o paradoxo de atrair não aliados. Novos estudos - CEBRAP, 78. Disponível em: http://www.scielo.br/scielo.php?script=sci_ arttext\&pid=S0101-33002007000200009\&lng=en\&nrm=iso, acesso em: 19/01/2008.

http://dx.doi.org/10.1590/S0101-33002007000200009

COLEMAN, S.; GØTZE, J. 2001. Bowling together: Online public engagement in policy deliberation. Londres, Hansard Society, $48 \mathrm{p}$.

COMPRASNET.2008. Acesso em: 05/12/2008, disponível em: http://www.comprasnet.gov.br.

DAGNINO, E. 2002. Sociedade civil e espaços públicos no Brasil. In: E. DAGNINO (ed.), Sociedade civil e espaços públicos no Brasil. São Paulo, Paz e Terra, p. 9-16.

DAHL, R. 2001. Sobre a democracia. Brasília, Universidade de Brasília, 230 p.

DELLICARPINI,M. 2000. Gen.com:Youth, civic engagement, and the new information environment. Political Communication, 17(4):341-349. http://dx.doi.org/10.1080/10584600050178942 DRYZEK, J.S. 2004. Legitimidade e economia na democracia deliberativa. In: V.S.P. COELHO; M. NOBRE, Participação e deliberação: teoria democrática experiências institucionais no Brasil contemporâneo. São Paulo, Editora 34, p. 41-62.

FERBER, P.; FOLTZ, F.; PUGLIESE, R. 2003. The politics of state legislature web sites: Making e-government more participatory. Bulletin of Science, Technology \& Society, 23(3):157-167. http://dx.doi.org/10.1177/0270467603023003002

FERBER, P.; FOLTZ, F.; PUGLIESE, R. 2005. The internet and public participation: State legislature web sites and the many definitions of interactivity. Bulletin of Science, Technology \& Society, 25(1):85-93. http://dx.doi.org/10.1177/0270467604271245 
FREEDOM HOUSE. 2006. Freedom in the world 2006: Selected data from freedom house's annual global survey of political rights and civil liberties. Acesso em: 01/09/2006, disponível em: www. freedomhouse.org/uploads/pdf/Charts2006.pdf.

FUNG, A. 2004. Empowered participation: Reinventing urban democracy. Oxford, Princeton University Press, 278 p.

GASTIL,J.2000. By popular demand: Revitalizing representative democracy through deliberative elections. Berkeley, University of California Press, 267 p.

GOMES, W. 2005. A democracia digital e o problema da participação civil na decisão política. Revista Fronteiras - Estudos Midiáticos, VIII(3):214-222.

HABERMAS, J. 2003. Direito e democracia: entre faticidade e validade. Rio de Janeiro, Tempo Brasileiro, $350 \mathrm{p}$.

HELD, D. 1987. Models of democracy. Stanford, Stanford University Press, $321 \mathrm{p}$.

HILL, K.; HUGHES, J. 1998. Cyberpolitics: Citizen activism in the age of the internet. New York, Rowman \& Littlefield, $207 \mathrm{p}$. KRUEGER, B.S. 2002. Assessing the potential of Internet political participation in the United States. American Politics Research, 30(5):476-498.http://dx.doi.org/10.1177/1532673X02030005002 KRUEGER, B.S. 2006. A comparison of conventional and internet political mobilization. American Politics Research, 34(6):759-776.http://dx.doi.org/10.1177/1532673X06290911 LÉVY, P. 1999. Cibercultura. Rio de Janeiro, Editora 34, 260 p. LIPINSKI, D.; NEDDENRIEP, G. 2004. using "new" media to get "old" media coverage: How members of congress utilize their web sites to court journalists. The Harvard International Journal of Press/Politics, 9(7):7-21.

MANIN, B. 1997. Principles of representative government. Cambridge, Cambridge University Press, 256 p. http://dx.doi.org/10.1017/CBO9780511659935

MARMURA, S. 2008. A net advantage? The internet, grassroots activism and American Middle-Eastern policy.New Media Society, 10(2):247-271. http://dx.doi.org/10.1177/1461444807086469 MARQUES, F. 2008. Participação política e internet: meios e oportunidades digitais de participação civil na democracia contemporânea, com um estudo do caso brasileiro. Salvador, BA. Tese de Doutorado. Universidade Federal da Bahia, 498 p.

MARQUES, F.; MIOLA, E. 2007. Internet e parlamento: um estudo dos mecanismos de participação oferecidos pelo Poder Legislativo através de ferramentas online. E-Compós, 9:1-20.

MIGUEL, L.F. 2003. Representação política em 3-D: elementos para uma teoria ampliada da representação política. Revista Brasileira de Ciências Sociais, 18(51):123-140.

MUSSO, J.; WEARE, C.; HALE, M. 2000. Designing web technologies for local governance reform: Good management or good democracy? Political Communication, 17(1):1-19.

http://dx.doi.org/10.1080/105846000198486

NEGROPONTE, N. 1995. A vida digital. São Paulo, Companhia da Letras, $231 \mathrm{p}$.
NOBRE, M. 2004. Participação e deliberação na teoria democrática: uma introdução. In: V.S.P. COELHO; M. NOBRE, Participação e deliberação: teoria democrática experiências institucionais no Brasil contermporâneo. São Paulo, Editora 34, p. 21-40. NORRIS, P. 2000. A virtuous circle: political communications in postindustrial societies. New York, Cambridge University Press, 416 p. http://dx.doi.org/10.1017/CBO9780511609343

NORRIS, P. 2001. Digital divide: Civic engagement, information poverty and the internet Worldwide. New York, Cambridge University Press, $320 \mathrm{p}$.

NOVECK, B.S. 2004. The future of citizen Participation in the Electronic State: Modeling Communicative Action in E-Rulemaking Practice. In: INTERNATIONAL WORKING CONFERENCE ON THE LANGUAGE-ACTION PERSPECTIVE ON COMMUNICATION MODELLING, 9, New Brunswick, 2004. Anais... Rutgers University, The State University of New Jersey, New Brunswick, p. 1-32.

ONU. 2008. E-Government Survey. Acesso em: 15/02/2008, disponível em: http://www.unpan.org/egovkb/global_ reports/08report.htm.

PAPACHARISSI, Z. 2002. The virtual sphere: The internet as a public sphere. New media Es society, 4(1):9-27.

http://dx.doi.org/10.1177/14614440222226244

PORTAL DA CÂMARA DOS DEPUTADOS.2009. Acesso 01/03/2009, disponível em: http://www.camara.gov.br.

RECEITA FEDERAL. 2008. Acesso em: 05/12/2008, disponível em: http://www.receita.fazenda.gov.br.

SALTER, L. 2004. Structure and forms of use. A contribution to understanding the 'effects' of the Internet on deliberative democracy. Information, Communication E Society, 7(2):185-206. http://dx.doi.org/10.1080/1369118042000232648

SCHEUFELE, D.A.; NISBET, M. 2002. Being a citizen online: New opportunities and dead ends. Harvard International Journal of Press/Politics, 7(3):55-75.

SHULMAN, S. 2004. The internet still might (but probably won't) change everything. ISS: A Journal of Law and Policy, 1(1):111-145.

SOUZA, C. 2001. Construção e consolidação de instituições democráticas: papel do orçamento participativo. São Paulo em Perspectiva, 15(4):84-97.

STANLEY, J.W.; WEARE, C. 2004. The effects of internet use on political participation: Evidence from an agency online discussion forum. Administration \& Society, 36(5):503-527. http://dx.doi.org/10.1177/0095399704268503

STROMER-GALLEY, J. 2000. On-line interaction and why candidates avoid it. Journal of Communication, 50(4):111-132. http://dx.doi.org/10.1111/j.1460-2466.2000.tb02865.x

TAMBINI, D. 1999. New media and democracy: The civic networking movement. Nerw Media and Society, 1(3):305-329. http://dx.doi.org/10.1177/14614449922225609 
TRANSPARENCY INTERNATIONAL. 2007. Corruption perception report. Acesso em: 07/02/2008, disponível em: http:// www.transparency.org/policy_research/surveys_indices/cpi. TV CÂMARA. 2007. Entrevista à TV Câmara concedida no dia 07 de maio. Acesso em: 15/04/2008, disponível em: http://www.camara.gov.br/internet/TVcamara/default. asp?selecao $=$ MAT\&Materia $=49291$.

VERBA, S.; BRADY, H.; SCHOLZMAN, K. 1995. Voice and Equality: Civic Volunteerism in American Politics. Cambridge, Harvard University Press, 640 p.
VITALE, D. 2007. Representação política e participação: reflexões sobre o déficit democrático. Rev. katálysis, 10(2):143-153. WEBER, L.; LOUMAKIS, A.; BERGMAN, J. 2003. Who participates and why? An analysis of citizens on the internet and the mass public. Social Science Computer Review, 21(1):26-42. http://dx.doi.org/10.1177/0894439302238969

Submetido em: 03/09/2009 Aceito em: 15/10/2009 